Research Article

\title{
The Establishment of Segmented Constitutive Relationship of Coal under Triaxial Compression: Take the No. 3 Coal of Xinhe Colliery as an Example
}

\author{
Yongjie Yang $\mathbb{D}^{1,2}$ Yang Zhang $\mathbb{D}^{1,2}$ and Tianli Zhang ${ }^{1,2}$ \\ ${ }^{1}$ College of Mining and Safety Engineering, Shandong University of Science and Technology, Qingdao 266590, China \\ ${ }^{2}$ State Key Laboratory of Mining Disaster Prevention and Control Co-founded by Shandong Province and the Ministry of Science \\ and Technology, Shandong University of Science and Technology, Qingdao 266590, China
}

Correspondence should be addressed to Yang Zhang; zhangyang57653@163.com

Received 15 April 2020; Revised 16 September 2020; Accepted 1 December 2020; Published 14 December 2020

Academic Editor: Damien Rangeard

Copyright (C) 2020 Yongjie Yang et al. This is an open access article distributed under the Creative Commons Attribution License, which permits unrestricted use, distribution, and reproduction in any medium, provided the original work is properly cited.

Constitutive relationship of coal under triaxial compression must be determined during solving the theoretical calculation and numerical simulation about coal body failure. This paper carried out the conventional triaxial compression test on No. 3 coal of Xinhe Colliery using the MTS815.03 servo-controlled rock mechanical test system. The results indicate that the failure process of coal can be divided into 5 stages: densification stage, apparent linear elastic deformation stage, accelerated inelastic deformation stage, fracture and developing stage, and plasticity flow stage. Within the test confining pressure (20 MPa), the peak strain of coal is approximately linearly positively correlated with the confining pressure. The relationship between elastic modulus of coal and confining pressure is quadratic polynomial. The triaxial compressive strength and residual strength of coal are approximately linearly positively correlated with confining pressure. The constitutive relationship model of coal can be simplified as the four segments of straight line model of "elastic-plastic hardening-plastic softening-residual perfectly plastic." Through fitting calculation of test data, the segmented constitutive equation of coal can be obtained, and the every segment span of strain.

\section{Introduction}

In the past triaxial compression experiments, there are abundant achievements on the mechanical properties and constitutive relations of hard, dense, and relatively homogeneous rocks, such as granite, marble, and red sandstone. Chen [1] has studied the effect of grain size on the mechanical properties of red sandstone. Chen [2] has studied the three-dimensional extension model of red sandstone with different opening surface cracks. Wen [3] has studied the heterogeneous rock damage constitutive model based on strain energy density. Ren [4] has studied the mesoscopic mechanism of rock damage evolution under uniaxial compression and constructed its constitutive model. Zhao [5] constructed the rock in the triaxial plus constitutive model during unloading. Yao [6] proposed a framework for describing the modulus degradation behavior of cement- treated soft clay by studying cement. Foreign scholars Menezes and Mishra [7, 8] have studied the volume change and failure process of jointed rock, hard sandstone, and shale under the triaxial compression test. While the coal belonging to sedimentary rocks differ greatly in composition and structure from these hard rocks, the beddings, joints, pores, and fractures of coal are complex and versatile, and its components differ in thousands ways; so, its strength is very low and the discreteness is large $[9,10]$. Therefore, the constitutive relations of different types of coal and rock are different, and the specific constitutive relations of coal and rock must be obtained through compression test analysis. Just like the other sedimentary rock, the strength and deformation characteristics are mainly influenced by the occurrence condition especially ground stress environment, except for components and structure. During the mining, coal is usually under the action of certain ground stress and 
the influence of mining [11]. There are few cases of uniaxial loading; except around the mining space, they are all in the state of triaxial stress [12]. So, the constitutive relationship under triaxial compression of coal must be determined when solving coal failure using the theory and numerical calculation method. So, carrying out the test about strength and deformation characteristic of coal under triaxial compression and further determining the constitutive relationship of coal is of important theoretical and practice meaning.

In the study of the constitutive model, the research results of coal constitutive models under uniaxial compression are rich. Fan [13] studied the rock creep characteristics and constitutive model of coal gas reservoirs. Dai et al. [14] derived the uniaxial using the results of CT experiments under the uniaxial compression conditions of coal under uniaxial compression. Research on establishing the constitutive model of elastic brittle damage of coal under the compression load is lacking. Wang and Yang [15] constructed a statistical damage constitutive model for coal uniaxial loading. However, the experimental research on the mechanical properties of coal under triaxial compression is still scarce. Liang et al. [16] studied the hydraulic fracturing ductile failure model of coal based on the constitutive relationship of cohesive cracks. Guo and Qi have studied the characteristics of coal after impact deformation and its constitutive model $[17,18]$. However, the study of the coal constitutive relation system based on the triaxial compression test considering strength discreteness has not been reported yet.

This paper carried out conventional triaxial compression experiment on No. 3 coal of Xinhe Colliery using the MTS815.03 servo-controlled rock mechanical test system. And its triaxial compression strength and deformation characteristics are analyzed. On this basis, through the simplification of the model, the three-axis compression constitutive equation of coal and rock is obtained by fitting.

\section{Experiment Method and Coal Sample Preparation}

2.1. Experiment Method. The conventional triaxial compression test was carried out on the MTS815.03 servocontrolled rock mechanical test system of Shandong University of Science and Technology. The experiment method is as follows: first, the sample was confining compressed to certain predetermined value, and then, the sample was compressed to failure on the axial strain velocity of $1.5 \times 10^{-5} \mathrm{~mm} / \mathrm{mm} / \mathrm{s}$.

2.2. Coal Sample Preparation. Because coal bedding and joints are very developed, there are many micropores and cracks, so the coal is weak and broken, the strength is low, and the dispersion is large. When the mechanical properties test is carried out, the sampling state of coal is very difficult because the original state of coal during sampling and preparation is highly susceptible to disturbance by human factors. No. 3 coal sample of Xinhe Colliery was adopted in this test. The coal block was taken from the return airway of the 5309 fully mechanized caving face of the mine. In the process of sampling and sample preparation, in order to keep the original state of the coal sample as much as possible and reduce the influence of human disturbance, the following main measures were taken: (1) Large coal samples are taken from the return airway $100 \mathrm{~m}$ away from the front of the two work face. In order to eliminate the influence of the supporting pressure in front of the working face, the large coal taken in the vertical direction belongs to the same layered coal and is in the vicinity of the same position in the horizontal direction. (2) In order to control the artificial cracks generated in the coal block during the sampling process effectively, a large coal sample is obtained by using a drilling machine to intensively drill the eye in the underground well and is immediately packaged and labeled. After the large coal is raised, it will be delivered to the laboratory for processing as soon as possible. (3) In the process of drilling, cutting, and grinding large coal samples in the laboratory, dry drill, dry cutting, and dry grinding are used as much as possible during the processing. Reduce machine speed as much as possible to reduce the effects of human disturbance. (4) Perform the sound wave velocity test on the processed coal sample in time and make a record. (5) The height, diameter, flatness, smoothness, and parallelism of the coal sample after processing can reach the rock test specification standard. In order to minimize the influence of the dispersion of mechanical properties of coal samples on the test results, Yang [19] proposed a test technique for the study of the discrete strength of the same rock. Seven samples that came from two adjacent large coal bodies with near longitudinal wave velocity and without an obvious surface defect were chosen to participate in the triaxial compression test. The coal samples that participate in the triaxial compression test conditions are shown in Table 1.

\section{Triaxial Compression Strength and Deformation Characteristics of Coal}

3.1. Deformation and Failure Process of Coal under Triaxial Compression. Principal stress differential-axial strain curve of coal sample under conventional triaxial compression is as shown in Figure 1, and the characteristic value of results is as shown in Table 2.

Figure 1 shows that the process of triaxial compression deformation and failure of coal and rock can be divided into five stages:

Densification stage: there are a large number of defects such as primary pores, fissures, bedding, and joints in the coal. Under load, these defects are compacted and closed; appearing on the stress-strain curve, the curve is concave upward, and the strain rate is greater than the stress rate.

Apparent linear elastic deformation stage: macroscopically, this stage is approximately linear elastic, and the stress-strain curve is linear and continuous. Microscopically, the deformation and rupture of coal is discontinuous and paroxysmal [20]. At this stage, the deformation in the coal body is mostly reversible, and 
TABLE 1: Basic parameters of coal samples.

\begin{tabular}{|c|c|c|c|c|c|c|c|}
\hline $\begin{array}{l}\text { Number of } \\
\text { coal samples }\end{array}$ & $\begin{array}{l}\text { Diameter } \\
(\mathrm{mm})\end{array}$ & $\begin{array}{c}\text { Height } \\
(\mathrm{mm})\end{array}$ & $\begin{array}{l}\text { Longitudinal wave } \\
\text { velocity }(\mathrm{mm} / \mathrm{s})\end{array}$ & $\begin{array}{l}\text { Transversal wave } \\
\text { velocity }(\mathrm{mm} / \mathrm{s})\end{array}$ & $\begin{array}{c}\text { Confining } \\
\text { pressure }(\mathrm{MPa})\end{array}$ & $\begin{array}{l}\text { Estimated axial } \\
\text { strength (MPa) }\end{array}$ & $\begin{array}{l}\text { Estimate elastic } \\
\text { modulus (MPa) }\end{array}$ \\
\hline XTT1 & 49.9 & 97.7 & 2063.00 & 1084.17 & 2 & 19.12 & 2761.15 \\
\hline XTT2 & 49.8 & 100.2 & 2088.28 & 1211.36 & 5 & 19.56 & 2804.56 \\
\hline XTT3 & 49.7 & 99.3 & 2139.89 & 1268.56 & 8 & 20.49 & 2903.88 \\
\hline XTT4 & 49.9 & 98.8 & 2161.90 & 1212.52 & 11 & 20.9 & 2950.62 \\
\hline XTT5 & 49.8 & 96.4 & 290.25 & 1330.02 & 14 & 21.44 & 3014.67 \\
\hline XTT6 & 49.8 & 97.4 & 2199.54 & 1151.45 & 17 & 21.62 & 3036.60 \\
\hline XHT7 & 49.9 & 95.6 & 2231.45 & 1241.22 & 20 & 22.25 & 3115.49 \\
\hline
\end{tabular}

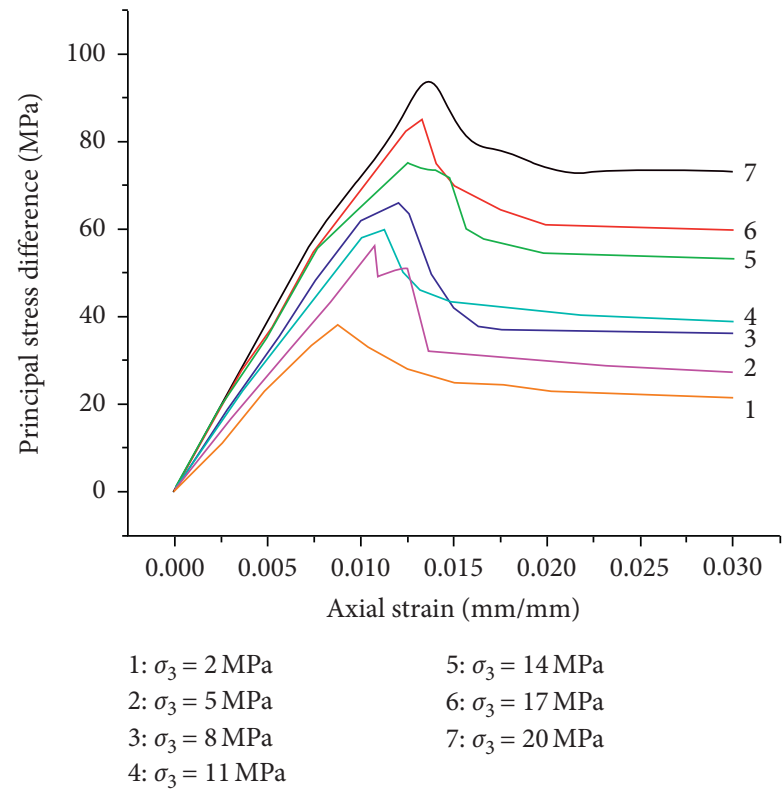

Figure 1: Curves of difference of principle stresses versus strain under different confining pressure of coal samples.

TABLE 2: Test results of Xinhe No. 3 coal samples under different confining pressure.

\begin{tabular}{|c|c|c|c|c|c|c|c|c|}
\hline Confining pressure $\sigma_{3}(\mathrm{MPa})$ & 0 & 2 & 5 & 8 & 11 & 14 & 17 & 20 \\
\hline Peak value $\sigma_{s}(\mathrm{MPa})$ & 21.07 & 39.13 & 59.04 & 67.99 & 76.77 & 89.91 & 103.77 & 113.32 \\
\hline Peak strain $\varepsilon_{s}(\mathrm{~mm} / \mathrm{mm})$ & 0.00664 & 0.00879 & 0.01059 & 0.01103 & 0.01189 & 0.01277 & 0.01306 & 0.0137 \\
\hline Elastic modulus $E(\mathrm{MPa})$ & 2758 & 4472 & 5133 & 5876 & 6621 & 6763 & 6982 & 7173 \\
\hline Residual strength $\sigma_{r}(\mathrm{MPa})$ & 2.5 & 23 & 32.1 & 49.6 & 48.1 & 66.6 & 77.7 & 93.4 \\
\hline
\end{tabular}

most of the deformation can be recovered after unloading, but there is still a small part of residual deformation, that is, there is a small part of plastic deformation. This is caused by dislocation slips between particles and inside the particles. Therefore, this stage is strictly not a linear elastic deformation, which can be called the apparent elastic deformation stage.

Accelerated inelastic deformation stage: after the elastic deformation stage of the apparent line, a large number of cracks with large scale appear in the coals, which reduce the bearing capacity of the coal body. At this stage, the coal accumulates enough energy, and the deformation begins to accelerate. The load rises relatively slowly, and a large number of microcracks generated in the coal body merge and penetrate, and eventually, the damage is unstable. At the end of this phase, the coal will deform even if the load is kept constant.

Fracture and developing stage: after the coal body is unstable and destroyed, the stress is gradually reduced, the deformation is increased, and the crack is encrypted Plasticity flow stage: with the continuous development of plastic deformation, the coal body finally reaches the stage of residual strength of looseness fracture

3.2. Relationship between Peak Strain and Confining Pressure of Coal Samples. The strain at which the coal sample reaches the peak strength is called the peak strain. Figure 2 is a scatter plot of the relationship between peak strain and confining 


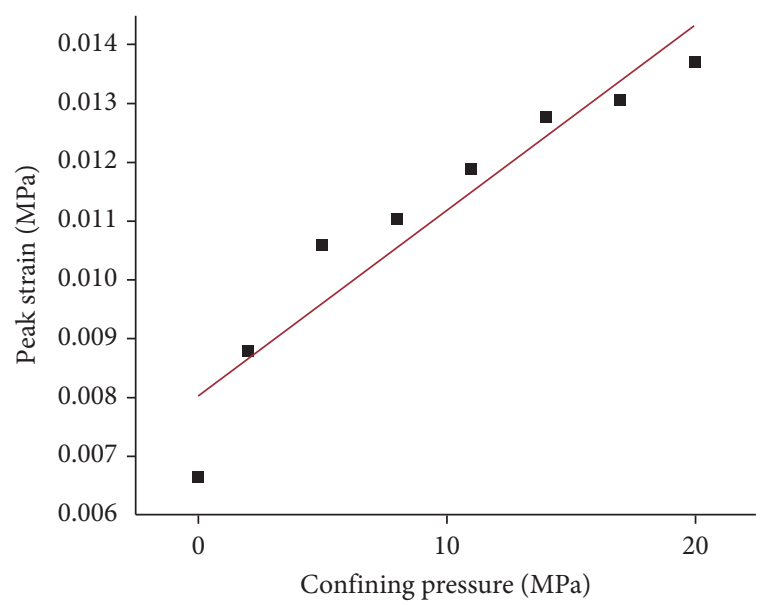

FIGURE 2: Relationship between peak strain and confining pressure of coal samples.

pressure of coal samples. It can be seen that as the confining pressure increases, the peak strain increases. The deformation of coal is characterized by the transformation of brittle failure under low confining pressure to plastic failure under high confining pressure. It shows that the deformation and failure of coal is closely related to the stress state in addition to its composition and structure. The fitting shows that there is a linear positive correlation between the peak strain and confining pressure of coal rock. The data of the uniaxial compression test does not participate in regression, correlation coefficient 0.9491 , and the regression relationship is as follows:

$$
\varepsilon_{s}=0.0003 \sigma_{3}+0.008 \text {. }
$$

\subsection{Relationship between Elastic Modulus of Coal and Confining Pressure}

3.3.1. The Method of Elastic Modulus Determination. Rock is not a fully elastic material. The International Society of Rock Mechanics recommends using any of the following three methods to determine the elastic modulus of rock [21].

(1) Tangent modulus where $\sigma=(1 / 2) \sigma_{c}$

$$
E=\left(\frac{\mathrm{d} \sigma}{\mathrm{d} \varepsilon}\right)_{\sigma=(1 / 2) \sigma_{c}} .
$$

The uniaxial compressive strength of rock is $\sigma_{c}$

(2) Secant modulus where $\sigma=(1 / 2) \sigma_{c}$

$$
E=\left(\frac{\sigma}{\varepsilon}\right)_{\sigma=(1 / 2) \sigma_{c}} .
$$

(3) The elastic modulus approximates the average modulus of the straight line segment

The tangent slope for the first method is actually the slope of the tiny secant. Since the calculation involves a ratio of two small figures and the accuracy is difficult to grasp, so the determination method is less applied. The secant modulus in the second method depends on the strain at $50 \%$ strength of the stress. This value is significantly affected by the loading of the initial encrypted segment, especially for sedimentary rocks such as coal that are very developed for primary damage. So, this modulus of elasticity determined by this method varies greatly. The average modulus is the slope of the approximate straight line segment in the stressstrain curve, excluding the effects of the initial compaction phase. And this method is less affected by experimental conditions and has a clear mechanical meaning. Therefore, it is more scientific and reasonable to use the elastic modulus determined by the average modulus of the straight line segment.

\subsubsection{Relationship between Elastic Modulus of Coal and} Confining Pressure. From Figure 1, we can see that the slope of curves of principle stresses versus strain of coal samples becomes steeper significantly with the increase of confining pressure. It shows that the elastic modulus of coal increases with the increase of confining pressure.

Figure 3 is a scatter plot of the relationship between the elastic modulus of the coal sample and the confining pressure because there are large primary pore fractures and microstructures in coal. Under the action of confining pressure, the gap crack is closed tightly, the stiffness of the coal rock is increased, and the elastic modulus is increased. However, there is no linear relationship between the elastic modulus of coal and the confining pressure. When the confining pressure is small, the elastic modulus increases with the increase of the confining pressure. When the confining pressure is increased to a certain extent, the elastic modulus increases gradually as the confining pressure increases. When the confining pressure is increased to a certain extent, the rate of increase is getting smaller when the modulus of elasticity increases as the confining pressure increases. It is indicated that the pore cracks in the coal are tightly closed to a certain extent, then the confining pressure is increased, and the degree of compaction is weakened. The test results show that the elastic modulus of coal and the confining pressure are consistent with the quadratic polynomial relationship:

$$
E=A \sigma_{3}^{2}+B \sigma_{3}+C
$$

The regression relationship between the elastic modulus of coal sample and the confining pressure is as follows:

$$
\begin{aligned}
E= & -13.156 \sigma_{3}^{2}+455.79 \sigma_{3} \\
& +3138.1 \quad \text { (correlation coefficient } 0.973) .
\end{aligned}
$$

\section{Triaxial Compressive Strength of Coal Samples}

The maximum bearing capacity of rock under triaxial compression conditions is $\sigma_{S}$, and $\sigma_{s}$ is called the triaxial ultimate strength or triaxial compressive strength. After the rock sample is destroyed under constant confining pressure, 


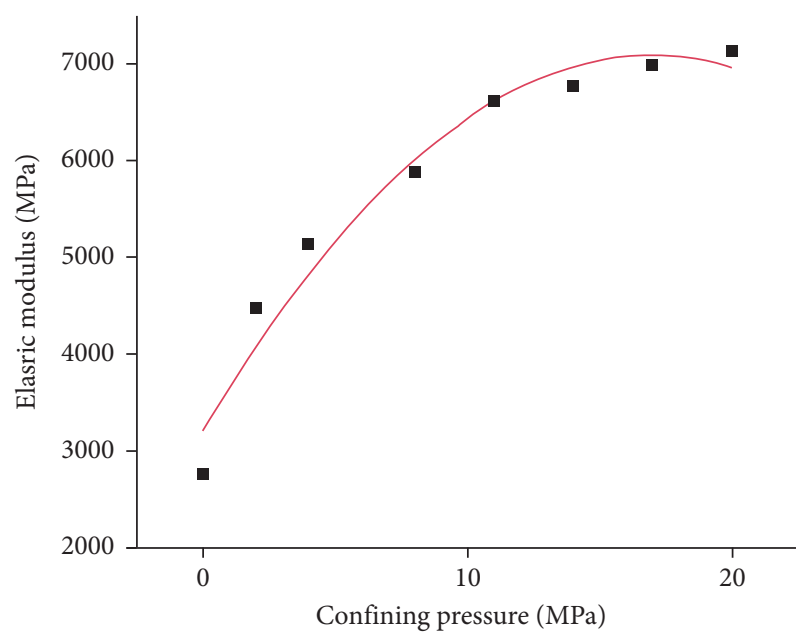

FIgURE 3: Relationship between elastic modulus and confining pressure of coal samples.

the axial stress that does not change with the increase of compression deformation in the stress-strain curve is called residual strength $\sigma_{r}$. Coals contain a lot of cracks, and its deformation will be affected by friction. The normal stress on the fracture surface is related to the confining pressure, and increasing the confining pressure is equivalent to increasing the normal stress on the fracture surface. The slip of the fracture surface is reduced by the suppression of the increased friction. Therefore, the ultimate strength of coal sample is increased. Therefore, the triaxial compressive strength and residual strength of coal and rock increase with the increase of confining pressure. Figure 4 shows the test results of the conventional triaxial compressive strength and residual strength of the coal sample and the confining pressure. It can be seen that the triaxial strength and residual strength of coal are approximately positively linearly related to the confining pressure.

4.1. The Analysis of Coal Stress Strength. Rock strength criterion is the criterion and condition for judging whether the stress and strain of rock are safe. It refers to the stress criterion and strain criterion in the limit state. At present, the strength criteria that are more suitable for the characteristics of geotechnical engineering include Coulomb criterion, Mohr criterion, Drucker-Prager criterion, Griffith criterion, and Hooke-Brown criterion [22-24]. Based on the results of conventional triaxial tests, this paper establishes the Coulomb strength criteria expressed for coal.

4.2. Criteria for Coal Stress Strength. The law of triaxial compressive strength of rocks under different confining pressures as a function of confining pressure is the stress intensity criterion. Under normal triaxial compression conditions, when $\sigma_{2}=\sigma_{3}$, the general form of rock failure criteria is as follows:

$$
\sigma_{1}=f\left(\sigma_{3}\right)
$$

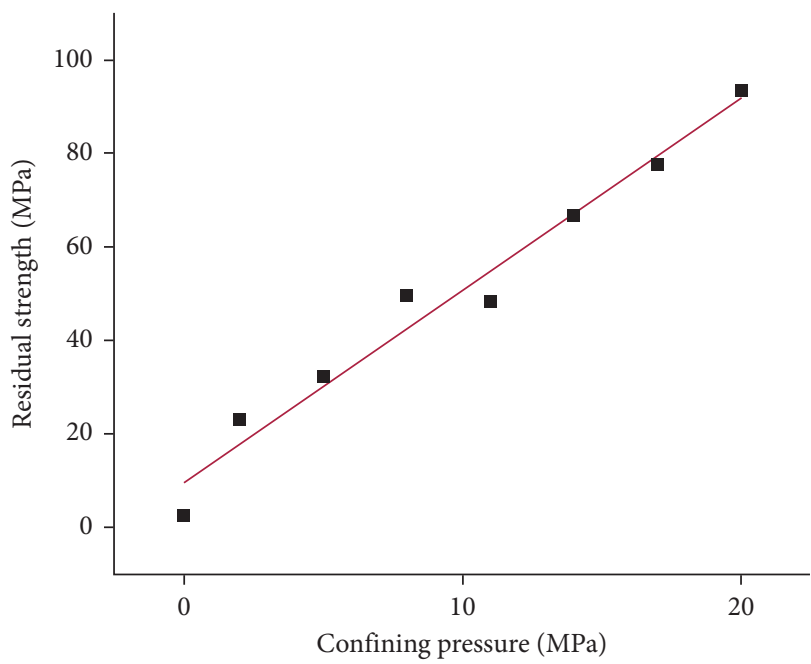

FIgURE 4: Relationship between triaxial strength and residual strength and confining pressure of coal samples.

In this formula, $\sigma_{1}$ and $\sigma_{3}$ are the maximum and minimum principal stresses in the limit stress state (i.e., peak point of triaxial compression), and the specific parameters in the above formula are determined by the test results.

From Figure 4, the triaxial compressive strength of coal samples and the confining pressure have a good linear relationship, and it can be expressed as a general form as follows:

$$
\sigma_{1}=A+B \sigma_{3} .
$$

The " $A$ " is equivalent to the uniaxial compressive strength of coal, and the " $B$ " is the coefficient of influence of confining pressure on triaxial strength. Because the coal sample is not a single shear failure during uniaxial compression, the uniaxial compressive strength of coal samples is significantly lower than the parameter " $A$ " for triaxial strength regression. It is best not to use it when returning to the Coulomb strength criterion.

In order to make formula (7) more general, the failure criterion should be dimensionless. Divide both sides of formula (7) by " $A$ " to get the following formula:

$$
\frac{\sigma_{1}}{A}=1+B \frac{\sigma_{3}}{A} .
$$

Let $K_{1}=B / A$, then get the following formula:

$$
\frac{\sigma_{1}}{A}=1+k_{1} \sigma_{3} .
$$

This formula is the expression of the strength criterion expressed in terms of principal stress, where " $k_{1}$ " is called the stress intensity parameter, which reflects the increase in the strength of the rock as the confining pressure increases. The No. 3 coal sample of Xinhe Colliery's $k_{1}$ is 0.1141 , and the regression coefficient is 0.99 . The strength criterion of No. 3 coal sample of Xinhe Colliery expressed in terms of principal stress is as follows: 


$$
\frac{\sigma_{1}}{A}=1+0.1141 \sigma_{3}
$$

Because the triaxial compressive strength of the No. 3 coal sample of Xinhe Colliery has a linear relationship with the confining pressure, its strength criteria are in line with the Coulomb strength criterion. According to this criterion, the maximum shear stress $\tau$ that a rock can bear is determined by the bonding force $C$ and the internal friction force. And the internal friction is related to the internal friction coefficient and normal stress, and the relationship between them is as follows:

$$
\tau=C+\mu \sigma
$$

In the formula, " $\mu$ " is the internal friction coefficient, $\mu=\operatorname{tg} \varphi$, “ $\varphi$ " is the internal friction angle, and the " $\sigma$ " is the normal stress on the failure surface.

Formula (7) is the Coulomb strength criterion expressed by normal stress, and the relationship between " $A$," " $B$," and " $C$ " is as follows:

$$
\begin{aligned}
& A=\frac{2 c \cos \varphi}{1-\sin \varphi}, \\
& B=\frac{1+\sin \varphi}{1-\sin \varphi} .
\end{aligned}
$$

According to the above formula, the values of " $C$ " and " $\varphi$ " of No. 3 coal in Xinhe Colliery can be obtained. The Coulomb strength criterion expressed by shear stress of No. 3 coal in Xinhe Colliery is as follows:

$$
\tau=9.98+0.7462 \sigma
$$

4.3. Criteria for Coal Strain Strength. When yield and failure occur at a point in the rock, the conditions to be satisfied between the strain components are called the strain strength criterion. The stress and strain states of rocks are related by the constitutive relationship. In this sense, taking stress and strain states as failure criteria is equivalent. At present, whether it is the finite element calculation or the stability analysis of surrounding rocks, basically the failure criterion described by stress is used, that is, the abovementioned stress failure criterion. However, for the full stress-strain process curve of coal rock as shown in Figure 1, there is a multivalue correspondence between stress and strain. At this time, it cannot judge whether the coal rock is damaged by using the stress failure criterion. Only by combining the strain values can it be judged whether the coal rock is damaged.

Strain failure criteria are best established by analyzing test results expressed in strain. As shown in Figure 2, there is a stable linear regression relationship between the confining pressure of No. 3 coal in Xinhe Colliery and its corresponding ultimate strain. Therefore, the coal samples strain criterion is similar to the stress failure criterion and can also be expressed as follows:

$$
\begin{gathered}
\varepsilon_{1}=C_{1}+\sigma_{3}, \\
\frac{\varepsilon_{1}}{C_{1}}=1+\frac{D}{C_{1}} \sigma_{3} .
\end{gathered}
$$

Let $K_{2}=D / C_{1}$, then get the following formula:

$$
\frac{\varepsilon_{1}}{C_{1}}=1+K_{2} \sigma_{3} \text {. }
$$

The " $C_{1}$ " is equivalent to the ultimate strain of coal rock under uniaxial compression, and the " $D$ " is the influence coefficient of confining pressure on the triaxial compression ultimate strain. As with uniaxial compressive strength, the maximum strain value of coal samples during uniaxial compression is significantly lower than the regression coefficient " $C_{2}$ " of the maximum strain value of triaxial compression and confining pressure, and it is best not to use it during regression. The " $\sigma_{3}$ " is the minimum principal stress in the limit strain state. The coefficient " $K$ " is called the strain strength coefficient, and it reflects the degree of deformation that the rock can withstand when it breaks. For the No. 3 coal in Xinhe Colliery, the value of " $K_{2}$ " is 0.03371 .

Rewrite strain strength conditional formula (15) into a more convenient form, so it can be obtained from formula (9):

$$
\sigma_{3}=\frac{\sigma_{1} / A-1}{K_{1}} \text {. }
$$

Substituting above formula into formula (15), we can get the following formula:

$$
\frac{\varepsilon_{1}}{C_{1}}=1+\frac{K_{2}}{K_{1}}\left(\frac{\varepsilon_{1}}{A-1}\right) .
$$

Let $\gamma=K_{2} / K_{1}$, then get the following formula:

$$
\frac{\varepsilon_{1}}{C_{1}}=1+\gamma\left(\frac{\sigma_{1}}{A-1}\right),
$$

or

$$
\sigma_{1}=\left(\frac{1+\gamma \sigma_{1}}{A-\gamma}\right) C_{1} .
$$

The above formula is another form of the strain failure criterion. The parameter " $\gamma$ " is called the strength scale factor, which represents the relationship between the stress intensity curve and the strain intensity curve.

As shown in Figure 5, if $\gamma>1$ and $K_{2}>K_{1}$, the strain intensity curve is above the stress intensity curve, indicating that the peak strain increases faster than the peak stress with increasing confining pressure. Conversely, if $\gamma<1, K_{2}<K_{1}$, and the strain intensity curve is below the stress intensity curve, it means that the peak stress increases faster than the peak strain with increasing confining pressure. If $\gamma=1$ and $K_{2}=K_{1}$, the stress and strain intensity curves coincide, indicating that as the confining pressure increases, the peak stress and peak strain increase simultaneously. It can be seen that $\gamma$ has a clear physical and geometric significance. Determine the slope of the two curves according to the test 


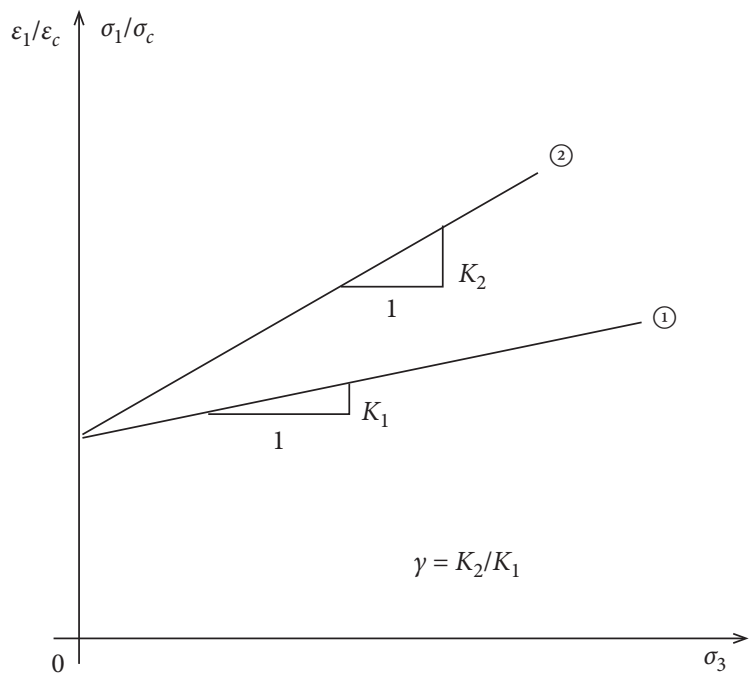

Figure 5: Sketch of stress and strain strength proportional ratio. (a) Stress intensity curve. (b) Strain intensity curve.

results, and the value of $\gamma$ can be obtained. For the No. 3 coal in Xinhe Colliery, the value of $\gamma$ is 0.2954 .

Through the above analysis, the strain strength criterion of No. 3 coal in Xinhe mine is as follows:

$$
\varepsilon_{1}=0.00063+7.5483 \times 10^{-5} \sigma_{1} .
$$

\section{Fitting Analysis of Triaxial Compression Constitutive Relation of Coal}

5.1. Simplification of the Constitutive Relationship Model. The results of the triaxial compression test of coal can be simplified to the main stress difference-strain curve as shown in Figure 6. As shown in the figure, the curve can be divided into 4 segments: densification and elastic segment $\mathrm{OB}$, plastic hardening segment $\mathrm{BC}$, plastic softening segment $\mathrm{CD}$, and residual segment $\mathrm{DE}$. Segment $\mathrm{OB}$ can be divided into densification section and elastic section, and point $A$ is the densified point. The occurrence of densification section is due to the densification of primary pores and fractures. The deformation of this stage was very complex, and it cannot be denoted by relation; it is not the main characteristic of coal mechanics property as well, so it is not taken into account in this model. Point $B$ is the yield strength point, point $C$ is the ultimate strength point, point $D$ is the initial point that the sample turn into residual strength, and point $E$ is the point of residual segment. The theoretic analysis of constitutive equation of every segment is shown as follows:

(1) Elastic segment $A B$

According to the generalized Hooke's law,

$$
\{\mathrm{d} \varepsilon\}=[C]\{\mathrm{d} \sigma\},
$$

or

$$
\{\mathrm{d} \sigma\}=[D]\{\mathrm{d} \varepsilon\}
$$

where $[D]=[C]^{-1}$.

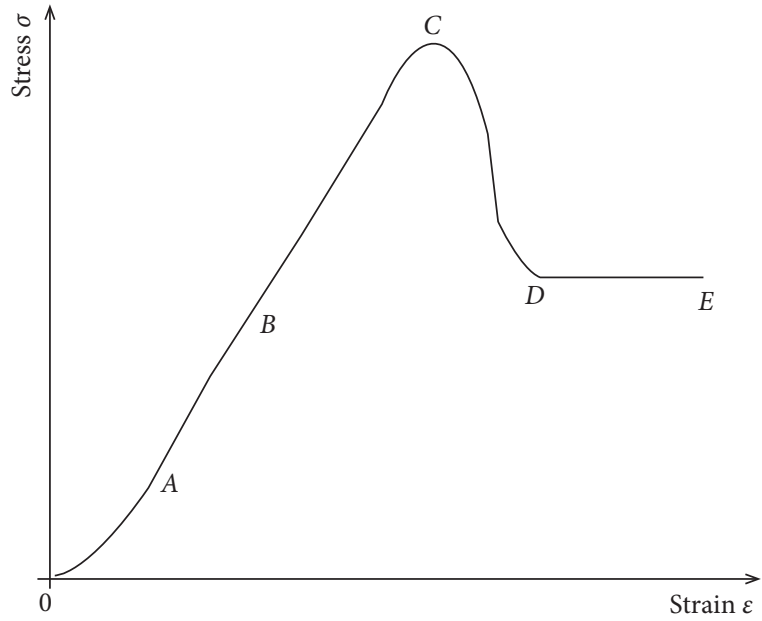

FIgURE 6: Typical whole stress-strain curve under triaxial compression.

(2) Plastic hardening segment BC

The constitutive relationship of this segment can be shown as

$$
\{\mathrm{d} \sigma\}=[D]_{\varepsilon}\{\mathrm{d} \varepsilon\}
$$

where $[D]_{\varepsilon}$ is the hardening coefficient.

(3) Plastic softening segment CD

This segment satisfied the Mohr-Coulomb yield criterion. According to plastic theory, Mohr-Coulomb condition can be shown as

$$
f_{1}=\sigma_{1}(1-\sin \phi)-\sigma_{3}(1+\sin \phi)-2 C \cos \phi,
$$

where $\phi$ is the inner friction angle, and Cis the cohesion.

This formula can be shown as follows:

$$
f=a \sigma_{1}+b \sigma_{3}+c
$$

where $a, b$, and $c$ are all the constants. 
(4) Residual segment DE

Residual segment can be considered as the residual plastic flow segment. In this stage, the yield surface remains constant, so the yield surface equation can be shown as

$$
f=c\left(\sigma_{1}, \sigma_{3}\right)
$$

where $a, b$, and $c$ are the constants.

According to the whole stress-strain curve of samples under conventional triaxial compression, four stages can be approximated to a linear relationship, and the simplified figure is as shown in Figure 6. The constitutive equation of 4 straight line segments of coal under conventional triaxial compression can be fitted according to test results.

\subsection{Fitting of Experimental Data for Constitutive Relation of} Triaxial Compression Coal. From Figure 7, the constitutive curve after simplification constituted of 4 straight line segments, and the fitting formula of former segments can be shown as the following unite formula:

$$
\sigma_{1}=a_{i} \varepsilon+b_{i}, \quad(i=1,2,3),
$$

where $a_{i}$ and $b_{i}$ denote the constants of segments $\mathrm{AB}, \mathrm{BC}$, and $\mathrm{CD}$ under fixed confining pressure.

Residual segment DE can be shown as

$$
\sigma_{1}=\sigma_{r}
$$

According to the experiment data, the value of $a_{i}, b_{i}$, and $\sigma_{r}$ can be calculated out, and the results are shown in Table 3 .

$a_{i}, b_{i}$, and $\sigma_{r}$ are the undetermined functions of $\sigma_{3}$, suppose as $f_{a_{i}}\left(\sigma_{3}\right), f_{b_{i}}\left(\sigma_{3}\right)$, and $f_{r}\left(\sigma_{3}\right)$, and they are fit out through data in Table 3 .

\section{Segment $A B$}

$$
f_{a_{1}}\left(\sigma_{3}\right)=-6.1034 \sigma_{3}^{2}+292.2 \sigma_{3}+3706.7
$$

(correlation coefficient 0.9898 )

$f_{b_{1}}\left(\sigma_{3}\right)=1.0202 \sigma_{3}+2.1487$

(correlation coefficient 0.9953 )

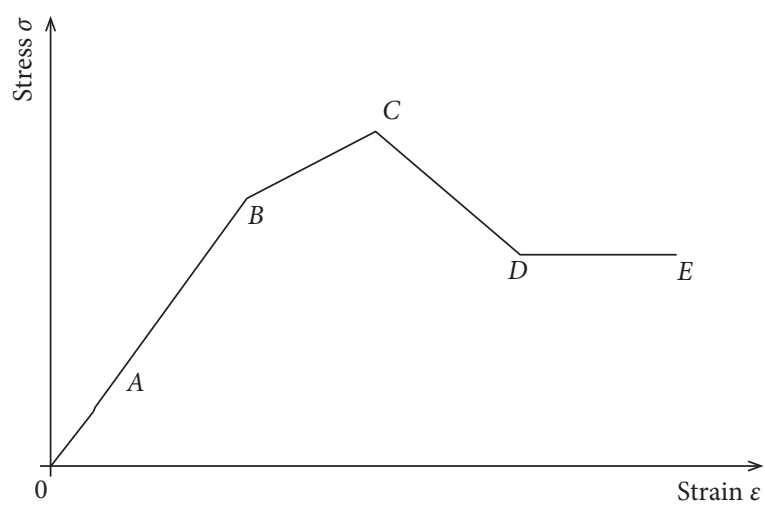

FIGURE 7: Simplified model of constitutive relation under triaxial compression.

Segment BC

$$
\begin{aligned}
& f_{a_{2}}\left(\sigma_{3}\right)=1.1605 \sigma_{3}^{3}-31.204 \sigma_{3}^{2}+296.71 \sigma_{3}+2919.7 \\
& \quad(\text { correlation coefficient } 0.6182) \\
& f_{b_{2}}\left(\sigma_{3}\right)=-0.1087 \sigma_{3}^{2}+4.0681 \sigma_{3}+0.7194 \\
& \text { (correlation coefficient } 0.8389)
\end{aligned}
$$

\section{Segment CD}

$$
\begin{aligned}
& f_{a_{3}}\left(\sigma_{3}\right)=-3.8891 \sigma_{3}^{3}+164.35 \sigma_{3}^{2}-1960.1 \sigma_{3}-461.09 \\
& \quad(\text { correlation coefficient } 0.7285) \\
& f_{b_{3}}\left(\sigma_{3}\right)=0.0445 \sigma_{3}^{3}-1.9329 \sigma_{3}^{2}+28.758 \sigma_{3}+24.299 \\
& \quad(\text { correlation coefficient } 0.9249)
\end{aligned}
$$

\section{Segment DE}

$$
\begin{aligned}
& f\left(\sigma_{3}\right)=3.8024 \sigma_{3}+13.96 \quad \text { (correlation coefficient } 0 . \\
& 9728)
\end{aligned}
$$

Colligating the fitting results of former experiment data, the constitutive equation of coal from Xinhe Colliery under conventional triaxial compression can be obtained:

$$
\left\{\begin{array}{l}
\sigma_{1}=\left(-6.1034 \sigma_{3}^{2}+292.2 \sigma_{3}+3706.7\right) \varepsilon+1.0202 \sigma_{3}+2.1487(\mathrm{AB}) \\
\sigma_{1}=\left(1.1605 \sigma_{3}^{3}-31.204 \sigma_{3}^{2}+296.71 \sigma_{3}+2919.7\right) \varepsilon-0.1087 \sigma_{3}^{2}+4.0681 \sigma_{3}+0.7194(\mathrm{BC}), \\
\sigma_{1}=\left(-3.8891 \sigma_{3}^{3}+164.35 \sigma_{3}^{2}-1960.1 \sigma_{3}-461.09\right) \varepsilon+0.0445 \sigma_{3}^{2}+28.758 \sigma_{3}+24.299(\mathrm{CD}), \\
\sigma_{1}=3.8024 \sigma_{3}+13.96(\mathrm{DE})
\end{array}\right.
$$


TABLE 3: Calculation results of fitted parameters.

\begin{tabular}{lcccccccc}
\hline \multirow{2}{*}{ Number of samples } & \multicolumn{2}{c}{ Confining pressure (MPa) } & \multicolumn{2}{c}{ Segment AB } & \multicolumn{2}{c}{ Segment BC } & \multicolumn{2}{c}{ Segment CD } \\
& & $a_{1}$ & $b_{1}$ & $a_{2}$ & $b_{2}$ & $a_{3}$ & $b_{3}$ & $\sigma_{r}$ \\
\hline XHT1 & 2 & 4199.5 & 4.9014 & 3047.6 & 12.341 & -3305.3 & 68.184 \\
XHT2 & 5 & 5061 & 6.7573 & 4601.3 & 10.313 & -8041.8 & 144.2 & 32.1 \\
XHT3 & 8 & 5811.4 & 10.044 & 3711.3 & 27.055 & -6297.9 & 137.46 & 49.6 \\
XHT4 & 11 & 6038 & 12.863 & 3337.7 & 37.085 & -7544.7 & 166.48 & 48.1 \\
XHT5 & 14 & 6636.5 & 16.64 & 3979.6 & 39.09 & -6283 & 170.14 & 66.6 \\
XHT6 & 17 & 6815.4 & 19.845 & 5466.8 & 32.373 & -5806.2 & 179.6 & 77.7 \\
XHT7 & 20 & 7176.8 & 22.542 & 5309.4 & 40.581 & -4835 & 179.56 & 93.4 \\
\hline
\end{tabular}

where the span of strain $\varepsilon$ of every segment is

$$
\left\{\begin{array}{l}
\mathrm{AB}:\left(2 E-05 \sigma_{3}+0.0003, \frac{-0.1087 \sigma_{3}^{2}+4.0681 \sigma_{3}-1.4293}{-1.1605 \sigma_{3}^{3}+25.1006 \sigma_{3}^{2}-4.51 \sigma_{3}+787}\right), \\
\mathrm{BC}:\left(\frac{-1087 \sigma_{3}^{2}+4.0681 \sigma_{3}-1.4293}{-1.1605 \sigma_{3}^{3}+25.1006 \sigma_{3}^{2}-4.51 \sigma_{3}+787}, \frac{0.0445 \sigma_{3}^{3}-1.8242 \sigma_{3}^{2}+24.6899 \sigma_{3}+23.5796}{5.0496 \sigma_{3}^{3}-195.554 \sigma_{3}^{2}+2256.81 \sigma_{3}+3380.79}\right), \\
\mathrm{CD}:\left(\frac{0.0445 \sigma_{3}^{3}-1.8242 \sigma_{3}^{2}+24.6899 \sigma_{3}+23.5796}{5.0496 \sigma_{3}^{3}-195.554 \sigma_{3}^{2}+2256.81 \sigma_{3}+3380.79}, \frac{-0.445 \sigma_{3}^{3}+1.9329 \sigma_{3}^{2}-24.9556 \sigma_{3}-10.339}{-3.8891 \sigma_{3}^{3}+164.35 \sigma_{3}^{2}-1960.1 \sigma_{3}-461.09}\right), \\
\mathrm{DE}:\left(\frac{-0.0445 \sigma_{3}^{3}+1.9329 \sigma_{3}^{2}-24.9556 \sigma_{3}-10.339}{-3.8891 \sigma_{3}^{3}+164.35 \sigma_{3}^{2}-1960.1 \sigma_{3}-461.09},+\infty\right) .
\end{array}\right.
$$

\section{Main Conclusions}

Carrying out conventional triaxial compression test on No. 3 coal of Xinhe Colliery using the MTS815.03 servocontrolled rock mechanical test system and using axial strain as the control variable of the system, the triaxial compression strength and deformation characteristics of coal and rock are analyzed. On this basis, the triaxial compression constitutive relation of coal and rock is studied.

(1) The results of conventional triaxial compression tests indicate that the failure process of coal can be divided into five stages: densification stage, apparent linear elastic deformation stage, accelerated inelastic deformation stage, fracture and developing stage, and plasticity flow stage

(2) The deformation characteristics of coal and rock under triaxial compression are obviously affected by confining pressure. Within the test confining pressure $(20 \mathrm{MPa})$, the peak strain of coal is approximately linearly positively correlated with the confining pressure, and the relationship between elastic modulus of coal and confining pressure is quadratic polynomial: $E=-13.156 \sigma_{3}^{2}+455.79 \sigma_{3}+3138.1$.

(3) Within the test confining pressure $(20 \mathrm{MPa})$, the triaxial compressive strength and residual strength of coal are approximately linearly positively correlated with confining pressure

(4) According to test results, the constitutive relationship model of coal can be simplified as the four segments of the straight line model of "elastic-plastic hardening-plastic softening-residual perfectly plastic." Through fitting calculation of test data, the segmented constitutive equation of sample from Xinhe Colliery No. 3 coal can be obtained.

\section{Data Availability}

The data used to support the finding of this study are included within the article.

\section{Conflicts of Interest}

The authors declare that they have no conflicts of interest.

\section{Acknowledgments}

This work was financially supported by the National Key Research and Development Program Funding (No. 2018YFC0604705) and the National Natural Science Foundation Project (No. 51574156). 


\section{References}

[1] S. J. Chen, Y. H. Guo, W. P. Huang, and D. W. Yin, "Experimental study of influence regularity and mechanism of particle size on mechanical properties of red sandstone," Journal of Shandong University of Science and Technology (Natural Science), vol. 36, no. 6, pp. 8-14, 2017.

[2] D. H. Chen, T. C. Li, X. A. Lu, and Y. Li, "Three-dimensional extension mode of red sandsone with different opening surface crack," Journal of Shandong University of Science and Technology (Natural Science), vol. 35, no. 5, pp. 63-69, 2016.

[3] Z. J. Wen, L. Tian, and J. Y. Jiang, "Study on damage constitutive model of heterogeneous rock based on strain energy density," Chinese Journal of Rock Mechanics and Engineering, vol. 35, no. 7, pp. 1332-1343, 2019.

[4] J. X. Ren and X. R. Ge, "Micromechanism and constitutive model of uniaxial compression rock damage evolution," Chinese Journal of Rock Mechanics and Engineering, vol. 20, no. 4, pp. 425-431, 2001.

[5] M. Zhao, X. V. Xibin, and X. V. Rong, "A constitutive model study of rock during triaxial loading and unloading," Chinese Journal of Rock Mechanics and Engineering, vol. 21, no. 5, pp. 626-631, 2002.

[6] K. Yao, Q. Chen, J. Ho et al., "Strain-dependent shear stiffness of cement-treated marine clay," Journal of Materials in Civil Engineering, vol. 30, no. 10, 2018.

[7] F. F. Menezes, "Anisotropy of volume change and permeability evolution of hard sandstones under triaxial stress conditions," Journal of Petroleum Science and Engineering, no. 174, pp. 921-939, 2019.

[8] B. Mishra and P. Verma, "Uniaxial and triaxial single and multistage creep tests on coal-measure shale rocks," International Journal of Coal Geology, vol. 137, no. 137, pp. 55-65, 2015.

[9] Y. J. Yang, D. C. Wang, and K. Wang, "Micro and mesodamage mechanism of coal's strength and deformation characteristics," Journal of University of Science and Technology, vol. 33, no. 6, pp. 653-557, 2011.

[10] N. G. W. Cook, "The failure of rock," International Journal of Rock Mechanics and Mining Sciences, no. 2, pp. 389-403, 1965.

[11] H. P. Kang, B. D. Yi, F. Q. Gao, and H. W. Lv, "Database and characteristics of underground in-situ stress distribution in Chinese coal mines," Journal of China Coal Society, vol. 44, no. 1, pp. 23-33, 2019.

[12] Z. P. Meng, S. P. Peng, and B. C. Ling, "Deformation and strength characteristics of sedimentary rocks under different lateral pressures," Journal of China Coal Society, vol. 25, no. 1, pp. 15-18, 2000.

[13] X. Y. Fan, Q. G. Zhang, W. Ai, and H. Q. Xia, "Research on creep property and constitutive model of rock in coal bed gas reservoir," Chinese Journal of Rock Mechanics and Engineering, vol. 32, no. 2, pp. 3732-3739, 2013.

[14] G. F. Dai, G. Z. Yin, and W. L. Pi, "Research on damage constitutive model and evolution equation of coal under uniaxial compression," Journal of Tongji University (Social Science Section), vol. 32, no. 8, pp. 986-989, 2004.

[15] C. Wang, X. B. Yang, and W. Q. Guo, "Uniaxial loading statistical damage constitutive model for coal and rock," Safety in Coal Mines, vol. 46, no. 11, pp. 10-13, 2015.

[16] W. G. Liang, J. F. Yang, H. J. Lian, and Z. Y. Wang, "Modelling ductile failure of coals in hydraulic fracturing based on the constitutive equations of cohesive cracks," Journal of China Coal Society, vol. 44, no. 1, pp. 263-270, 2019.
[17] D. Y. Guo, P. F. Lv, J. C. Zhao, and T. G. Zhu, "Deformation and damage characteristics and constitutive model of coal and rock under impact loading," Journal of China Coal Society, vol. 43, no. 8, pp. 2233-2242, 2018.

[18] L. F. Rong, C. M. Mu, and W. Q. Zhang, "Mechanical properties and establishment of constitutive relation of coal rock in 13 coal seam from Panxie coalfield under impact load," Journal of China Coal Society, vol. 40, no. 1, pp. 40-46, 2015.

[19] Y. J. Yang and S. J. Chen, "Experimental technology study on the discreteness of the same rock strength," Experimental Technology and Management, vol. 22, no. 1, pp. 34-37, 2005.

[20] Y. J. Yang, D. P. Ma, and Y. Zhou, "Experimental research on spectrum signature eigen of acoustic emission of coal and sandstone damage under triaxial unloading confining pressure," Journal of Mining \& Safety Engineering, vol. 36, no. 5, pp. 1002-1008, 2019.

[21] M. Q. You, "Effect of confining pressure on the Young's modulus of rock specimen," Chinese Journal of Rock Mechanics and Engineering, vol. 22, no. 1, pp. 53-60, 2003.

[22] R. E. Goodman, Principles of Rock Mechanics and their Applications, Water Resources and Electric Power Press, Beijing, China, 1990.

[23] M. Q. You, C. D. Su, and Y. Zhou, "Regression method for strength deformation characteristics and strength criterion of different coal blocks," Chinese Journal of Rock Mechanics and Engineering, vol. 22, no. 12, pp. 2081-2085, 2003.

[24] W. Liu, Z. Guo, S. Niu, J. Hou, F. Zhang, and C. He, "Mechanical properties and damage evolution behavior of coalfired slag concrete under uniaxial compression based on acoustic emission monitoring technology," Journal of Materials Research and Technology, vol. 9, no. 5, pp. 9537-9549, 2020. 